\title{
Hydrogen Embrittlement of Hardened Low-carbon Sheet Steel
}

\author{
Seok-Jae LEE, Joseph A. RONEVICH, George KRAUSS and David K. MATLOCK \\ Advanced Steel Processing and Products Research Center, Department of Metallurgical and Materials Engineering, Colorado \\ School of Mines, 1500 Illinois Street, Golden, CO 80401 USA.
}

(Received on July 2, 2009; accepted on October 22, 2009)

\begin{abstract}
Tensile specimens of 10B22 (22MnB5) sheet steels were austenitized, quenched to martensite, and tempered at temperatures between 150 and $520^{\circ} \mathrm{C}$ for various times. The heat treated specimens were charged with $1.7 \mathrm{ppm}$ hydrogen and immediately tested. Fracture surfaces were examined by field emission scanning electron microscopy. As-quenched martensitic specimens exhibited the most severe embrittlement and failed by stress-controlled cleavage fracture at low stresses. The initiation of hydrogen-induced fracture in specimens tempered between 150 and $350^{\circ} \mathrm{C}$ was consistent with glide plane decohesion, and coarse inclusion particles served as sources of hydrogen for circular areas of hydrogen-induced cleavage. Specimens tempered at 460 and $520^{\circ} \mathrm{C}$ showed little sensitivity to hydrogen embrittlement. The progression of decreased sensitivity to hydrogen-induced fracture with increasing tempering temperature correlates with the reduction in dislocations, the principal hydrogen traps, and the formation of cementite particles, considered to be ineffectual traps, with increased tempering. Very small amounts of intergranular fracture were observed, only in as-quenched specimens, confirming that boron has little effect on hydrogen embrittlement of hardened low-carbon steels.
\end{abstract}

KEY WORDS: hydrogen embrittlement; tempered martensite; low-carbon sheet steel; mechanical properties; SEM analysis; fracture mechanism.

\section{Introduction}

Low-carbon sheet steels quenched to martensite are increasingly being used for automotive parts that require ultrahigh strength for crash protection in side-impact and rollover accidents. Such steels have been long used in parts that require little changes in shape and therefore could be readily produced by roll forming. ${ }^{1)}$ However, recently steel parts with martensitic microstructures and more complicated shapes are being produced by hot stamping at temperatures where austenite is stable, followed by die quenching. ${ }^{2-6)} \mathrm{A}$ systematic study of the effect of tempering on sheet tensile specimens of AISI 10B22, a $0.22 \mathrm{wt} \% \mathrm{C}$ steel, alloyed with boron for hardenability and which corresponds to European grade 22MnB5, has shown that strengths between 1200 $\mathrm{MPa}$ and $1600 \mathrm{MPa}$ can be produced with little changes in ductility, about 6 to $8 \%$ in sheet tensile specimens, after tempering martensite between 150 to $350^{\circ} \mathrm{C}$. ${ }^{7,8)}$ Tempering at higher temperatures causes extensive discontinuous yielding, greatly reduced strain hardening, and lower strengths.

Steels, especially medium-carbon steels, typically containing $0.4 \mathrm{wt} \% \quad \mathrm{C}$, quench and tempered to ultrahigh strengths, are highly sensitive to hydrogen embrittlement. ${ }^{9,10)}$ In applications such as high-strength fasteners, electroplated with chromium or cadmium, hydrogen is introduced by the electroplating and must be removed by lowtemperature baking treatments, typically around $150^{\circ} \mathrm{C}$, to reduce sensitivity to hydrogen embrittlement. In mediumcarbon steels hydrogen embrittlement is typically character- ized by intergranular fracture at prior austenite grain boundaries with segregated atoms of phosphorus, antimony, tin, and arsenic. ${ }^{11,12)}$

In irons and low-carbon steels, hydrogen embrittlement may be characterized by trangranular fracture as well as intergranular fracture. The brittle transgranular fracture has been shown to occur on slip planes rather than the $\{100\}$ cleavage planes of body-centered-cubic structures, ${ }^{10,13,14)}$ a mechanism referred to as glide plane decohesion. Low carbon steels are extensively welded, and a damaging form of hydrogen embrittlement develops in heat-affected zones (HAZ) of low-carbon steel welds. This form of hydrogeninduced cracking is referred to as cold cracking and is strongly related to the formation of untempered martensite in HAZ. ${ }^{15)}$ As a result, carbon and other elements that promote hardenability are limited for high resistance to cold cracking. Both intergranular and transgranular fracture associated with hydrogen are observed in low-carbon steel welds.

In view of the current increased application of low-carbon sheet steels with martensitic microstructures for automotive applications, and the increased interest to use localized tempering to tailor parts with controlled property gradients required to simultaneously provide strength and energy absorbance in crash situations, ${ }^{16}$ ) the purpose of this paper is to report the results of a study that evaluated the effect of hydrogen on the mechanical behavior and fracture of as-quenched and quenched and tempered specimens of a low-carbon steel. The study was performed on the same 10B22 steel used for the earlier study of the mechanical 
properties of quench and tempered specimens not exposed to hydrogen. ${ }^{7,8)}$ The specimens in the current study were tested immediately after hydrogen charging, and recent work by thermal desorption spectrometry on hydrogen trapping capability of quench and tempered low-carbon steels, ${ }^{17,18)}$ coupled with the results of mechanical testing and fractographic analysis of this investigation, provide useful information contributing to understanding hydrogen embrittlement of the heat treated 10B22 steel.

\section{Experimental Procedure}

The chemical composition of the low-carbon steel is given in Table 1. Boron is effectively used in low carbon steels to provide hardenability, and several studies have shown that boron additions in steel have little effect on hydrogen embrittlement. ${ }^{19,20)}$ Standard ASTM E-8 longitudinal tensile samples were machined from $1.7 \mathrm{~mm}$ thick commercially produced cold-rolled sheet steel. The tensile samples were austenitized at $900^{\circ} \mathrm{C}$ for $10 \mathrm{~min}$ in a salt bath and quenched in water. The quenched samples were tempered at temperatures between $150^{\circ} \mathrm{C}$ and $520^{\circ} \mathrm{C}$ for times of $600 \mathrm{~s}$, $3600 \mathrm{~s}$, and $36000 \mathrm{~s}$ in either oil or salt baths and air cooled after tempering.

The tensile samples were cathodically charged with hydrogen with a DC power supply in a solution of $1 \mathrm{~N} \mathrm{H}_{2} \mathrm{SO}_{4}$ with $1 \mathrm{mg} / \mathrm{L} \mathrm{As}_{2} \mathrm{O}_{3}$ as a hydrogen recombination poison. ${ }^{21)}$ Charged coupons, $7 \times 7 \times 1.5 \mathrm{~mm}^{3}$, were used to determine induced hydrogen content in a LECO RH-404 hydrogen analyzer, and parameters were established to induce a constant hydrogen content of $1.7 \mathrm{ppm}$ in all samples. A current density of $5 \mathrm{~mA} / \mathrm{cm}^{2}$ for $30 \mathrm{~min}$ was used for the asquenched samples and $10 \mathrm{~mA} / \mathrm{cm}^{2}$ for $30 \mathrm{~min}$ was used for the tempered samples. The grip and fillet sections of the tensile specimens were covered with plastic coated tape to prevent contact with the solution during charging. After charging, solution remaining on specimen surfaces was removed with a paper towel, the plastic tape was removed, and tensile tests were started with a minimum delay time of less than 1 or $2 \mathrm{~min}$. In order to ensure that the hydrogen contents of the tensile samples could be viewed as essentially constant during the time between charging and final fracture in tensile testing, hydrogen contents in samples representative of the two end points of the microstructural conditions, i.e. as-quenched and after quenching and tempering for $10 \mathrm{~h}$ at $520^{\circ} \mathrm{C}$, were measured immediately after charging and after a delay equivalent to the longest total time to failure. The measured hydrogen contents after the delay were equivalent to the $1.7 \mathrm{ppm}$ initially introduced in the samples. This observation indicates that even for the high temperature tempered material where the microstructure after tempering was primarily ferrite with a fine dispersion cementite, ${ }^{36)}$ the diffusionable hydrogen was trapped in the material and unable to escape even though simple diffusion predictions for hydrogen migration in ferrite would

Table 1. Chemical composition (mass\%) of AISI 10B22 steel used in this study.

\begin{tabular}{|c|c|c|c|c|c|c|c|c|c|}
\hline $\mathrm{C}$ & $\mathrm{Mn}$ & $\mathrm{Si}$ & $\mathrm{S}$ & $\mathrm{P}$ & $\mathrm{B}$ & $\mathrm{Ti}$ & $\mathrm{Cr}$ & $\mathrm{N}$ & $\mathrm{Al}$ \\
\hline 0.224 & 1.046 & 0.256 & 0.0019 & 0.0103 & 0.0035 & 0.0395 & 0.2185 & 0.0044 & 0.0370 \\
\hline
\end{tabular}

suggest that the hydrogen diffusivity at room temperature (on the order of $10^{-4} \mathrm{~cm}^{2} \mathrm{~s}^{-1}$ ) was sufficiently high to allow the hydrogen to migrate through the sheet samples. ${ }^{21)}$

All tensile tests were performed at a constant crosshead speed of $2.54 \mathrm{~mm} / \mathrm{min}$. The results from testing of hydrogen-charged specimens were compared to those made in the earlier investigation of the same steel without hydrogen. ${ }^{7,8)}$ Fracture surfaces of selected hydrogen-embrittled samples were examined with a field emission scanning electron microscope (SEM).

\section{Results}

\subsection{Mechanical Testing}

Figure 1 compares hardness of hydrogen-charged and uncharged samples of the $0.22 \mathrm{wt} \% \mathrm{C}$ steel as a function of tempering conditions. There is little effect of hydrogen on hardness for all tempering temperature-time combinations shown. However, there is a severe effect of hydrogen on the tensile behavior of the as-quenched martensitic steel, Fig. 2. The hydrogen embrittled steel fails at very low stress, $400 \mathrm{MPa}$, with no apparent plasticity, while the uncharged as-quenched specimen reaches a tensile strength in excess of $1600 \mathrm{MPa}$ and fails in a ductile manner.

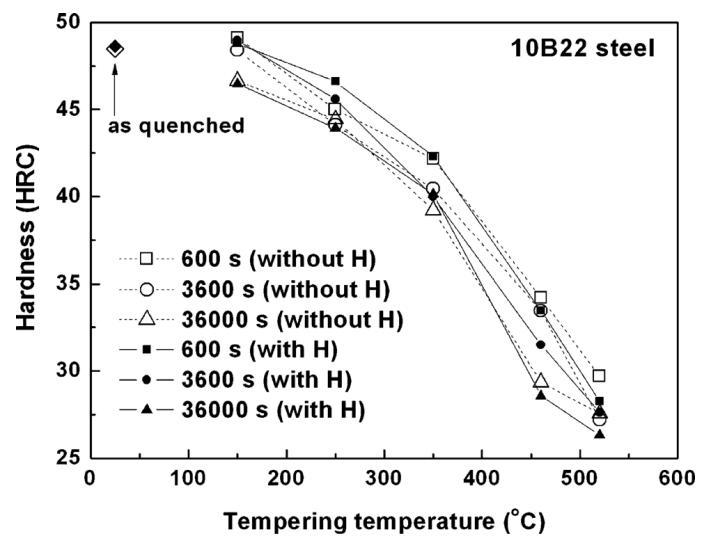

Fig. 1. Effect of the hydrogen charging on hardness change of 10B22 steel tempered according to tempering temperatures and holding times.

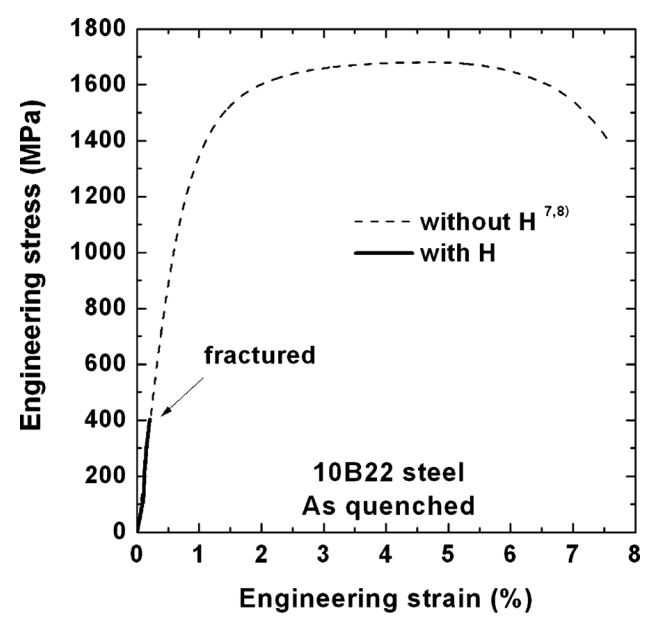

Fig. 2. Engineering stress-strain curves of $10 \mathrm{~B} 22$ steel after asquenching with considering the effect of the hydrogen charging. 


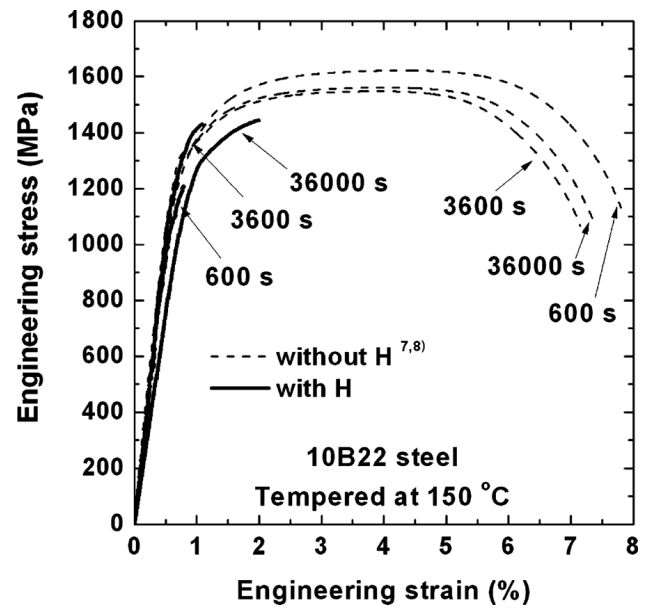

Fig. 3. Engineering stress-strain curves of $10 \mathrm{~B} 22$ steel with and without hydrogen charging after tempering at $150^{\circ} \mathrm{C}$ for $600 \mathrm{~s}, 3600 \mathrm{~s}$, and $36000 \mathrm{~s}$.

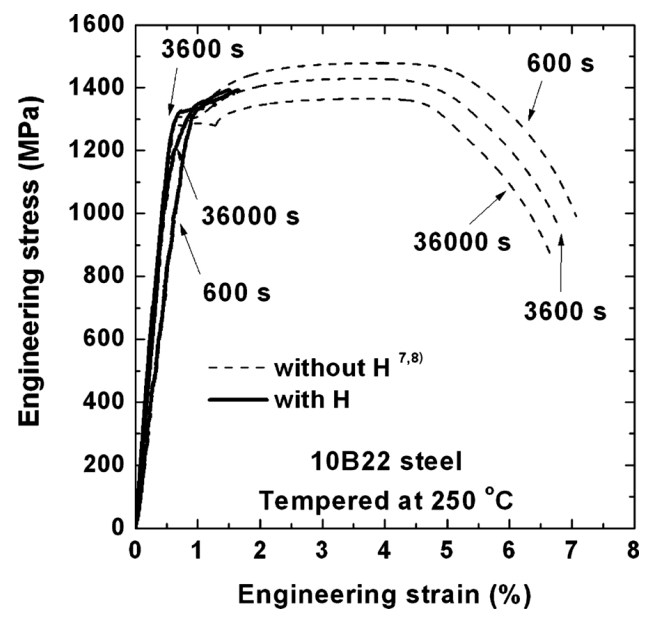

Fig. 4. Engineering stress-strain curves of 10B22 steel with and without hydrogen charging after tempering at $250^{\circ} \mathrm{C}$ for $600 \mathrm{~s}, 3600 \mathrm{~s}$, and $36000 \mathrm{~s}$.

The engineering stress-strain curves for hydrogencharged and uncharged samples of the martensitic lowcarbon steel tempered at various temperatures for various times are shown in Figs. 3 through 7. Selected tensile curves are plotted from the multiple tests run for each hydrogen charged. While not shown here, the curves exhibited excellent reproducibility, and derived tensile properties from all tests are considered in the figure associated with the strength-ductility analysis presented below. The data in Figs. 3 to 5 are plotted up to the point of peak load as the samples failed with limited post uniform strain outside the extensometer gage length. Data in Figs. 6 and 7 are shown to failure and thus show the uniform and post uniform contributions to the total ductility. At low tempering temperatures the hydrogen charged samples show some plasticity, but fracture at very low strains compared to uncharged samples. In specimens tempered at 150 to $350^{\circ} \mathrm{C}$, tempering time has little influence on mechanical behavior in hydrogen charged samples. Never the less, plasticity in the hydrogen charged samples increases noticeably with temperature. After tempering at $460^{\circ} \mathrm{C}$ and $520^{\circ} \mathrm{C}$, there is little difference, with a few exceptions, in the tensile performance of charged and uncharged samples.

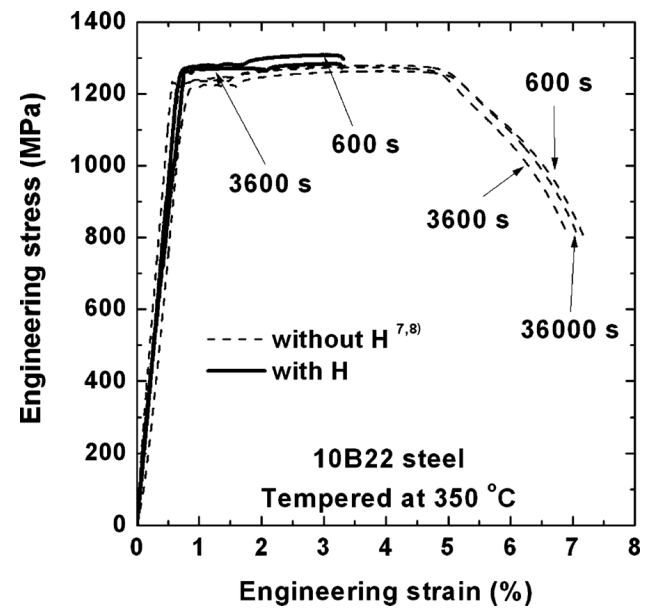

Fig. 5. Engineering stress-strain curves of $10 \mathrm{~B} 22$ steel with and without hydrogen charging after tempering at $350^{\circ} \mathrm{C}$ for $600 \mathrm{~s}, 3600 \mathrm{~s}$, and $36000 \mathrm{~s}$.

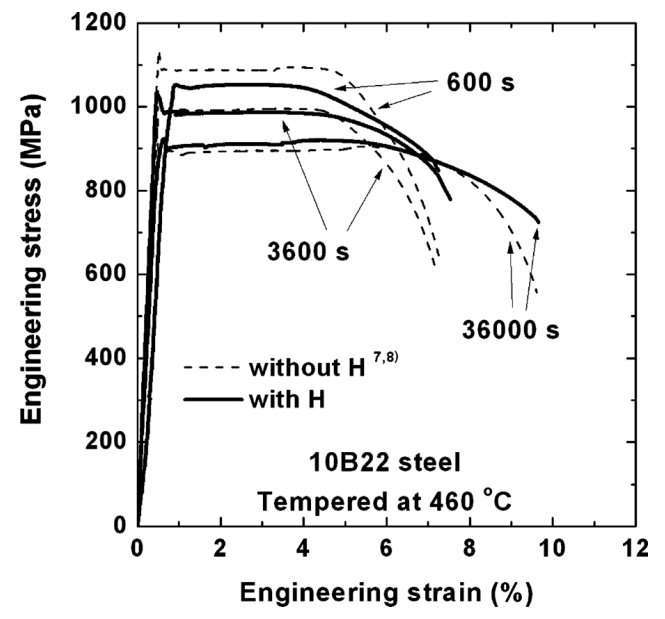

Fig. 6. Engineering stress-strain curves of $10 \mathrm{~B} 22$ steel with and without hydrogen charging after tempering at $460^{\circ} \mathrm{C}$ for $600 \mathrm{~s}, 3600 \mathrm{~s}$, and $36000 \mathrm{~s}$.

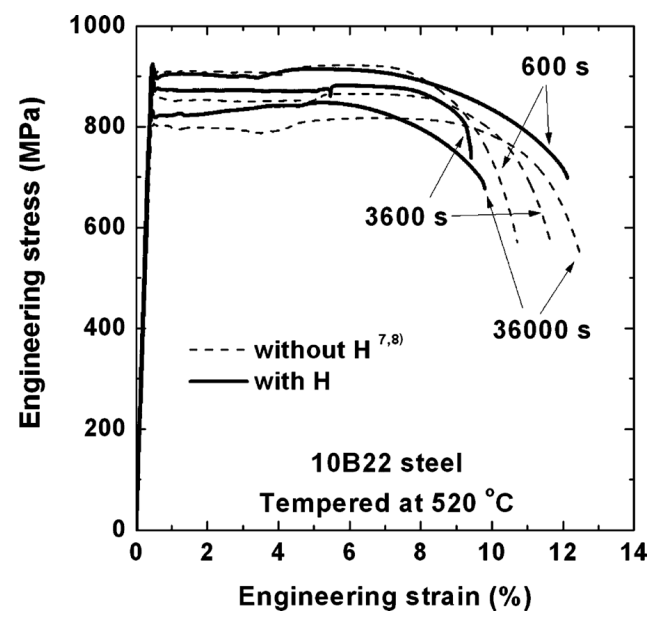

Fig. 7. Engineering stress-strain curves of $10 \mathrm{~B} 22$ steel with and without hydrogen charging after tempering at $520^{\circ} \mathrm{C}$ for $600 \mathrm{~s}, 3600 \mathrm{~s}$, and $36000 \mathrm{~s}$.

Figure 8 summarizes the results of tensile testing in a plot of maximum tensile strength versus total ductility for hydrogen charged and uncharged specimens. Except for the effect of hydrogen on specimens with as-quenched marten- 


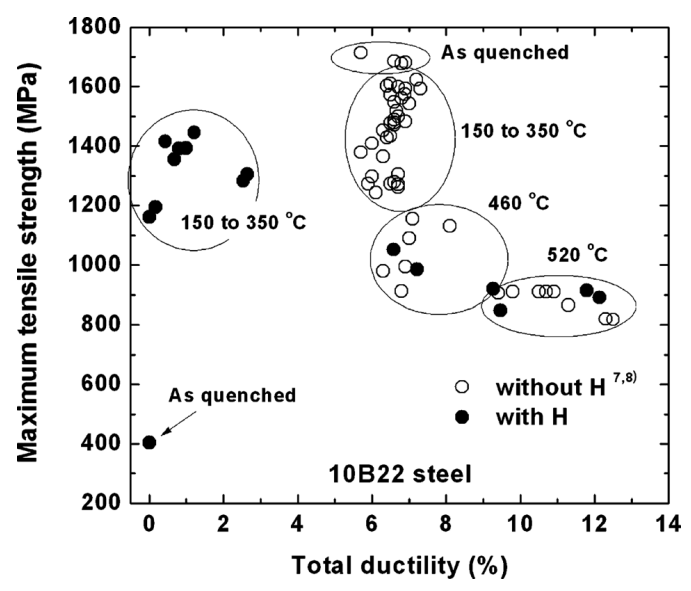

Fig. 8. Combinations of maximum tensile strength and total elongation with and without hydrogen charging for 10B22 steel tempered with various conditions.

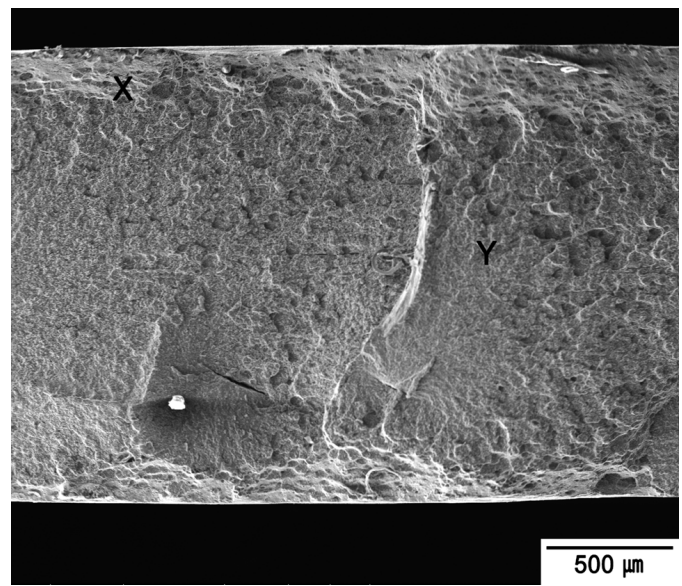

Fig. 9. Analysis of the tensile fracture surface at the middle of the sample of as-quenched hydrogen charged 10B22 steel. SEM micrograph.

sitic microstructures, maximum tensile strengths differ little in charged and uncharged samples in various tempered conditions. However, for specimens tempered at low temperatures, ductilities, and therefore fracture resistance, are drastically reduced by hydrogen.

\subsection{Fracture Characterization}

Fracture surfaces of specimens that showed the most severe reaction to hydrogen were selected for fracture evaluation. Fracture surfaces of tensile specimens with asquenched martensitic microstructures, and microstructures produced by tempering at $150^{\circ} \mathrm{C}$ for $3600 \mathrm{~s}$ and tempering at $250^{\circ} \mathrm{C}$ for $3600 \mathrm{~s}$ were selected. Each tensile specimen fracture surface showed areas of brittle fracture and ductile fracture, and emphasis was placed on the characterization of the brittle fracture areas.

Figure 9 shows a low-magnification view of a portion of the fracture surface of the as-quenched tensile specimen. Large areas of the fracture surface were flat, but some ductile fracture was associated with shear lips at the specimen edges, as marked by (X). The fracture in the area marked (Y) was completely brittle. There was a small amount of brittle intergranular fracture, as shown in Fig. 10, but the major portion of the brittle fracture consisted of a mix of

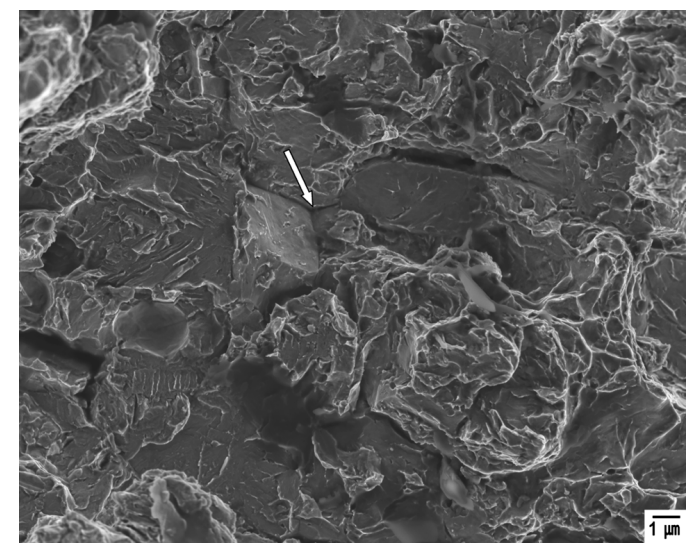

Fig. 10. Area of brittle fracture in hydrogen-charged, as-quenched specimen, taken in area (Y) of Fig. 9. Arrow points to area of intergranular fracture at a prior austenite grain boundary triple point. SEM micrograph.

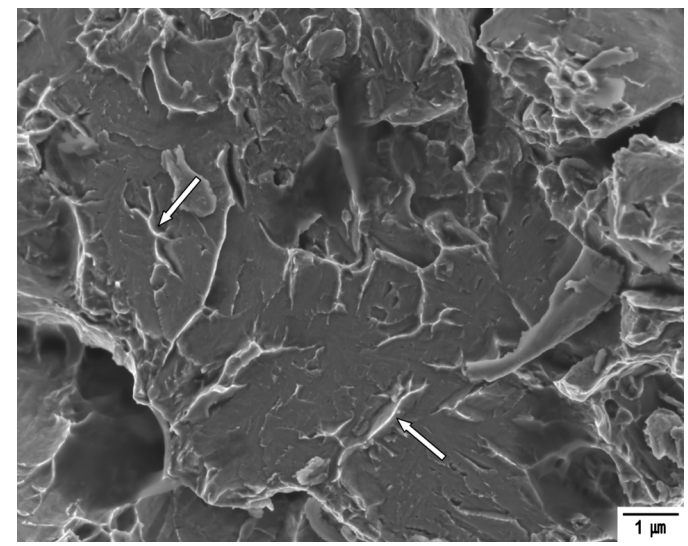

Fig. 11. Flat fracture facets in area marked (Y) in Fig. 9 of hydrogen-charged, as-quenched tensile specimen. Arrows point to fine secondary cracking. SEM micrograph.

fine and coarse flat facets. The mixed sizes of the various facets may be related to the hydrogen trapping effectiveness of lath, block, and packet boundaries and their effect on the cleavage facet size and inter-cleavage steps on the fracture surface of the low-carbon martensitic microstructure. Figure 11 shows a relatively large flat facet with a unique morphology of fine secondary cracking. The larger flat facets are unlike the cleavage facets that typically develop with distinct steps referred to as river patterns in steels tested below their ductile to brittle transition temperatrues. ${ }^{22}$ )

The low-magnification overview of the surface of a hydrogen-charged tensile specimen quenched to martensite and tempered at $150^{\circ} \mathrm{C}$ for $3600 \mathrm{~s}$ is shown in Fig. 12. The area marked (X) shows a mix of brittle and ductile fracture features, as illustrated in Fig. 13, a higher magnification image of one of the dark spots evident in Fig. 12. The fracture zone with mixed ductile and brittle fracture morphologies is characterized by circular fracture features that have formed around coarse inclusions. Figure 13 shows an example of one of the circular features. In this case the inclusion was an aluminum oxide, but other similar features were nucleated by sulfides or titanium-rich inclusions. Figure 14 shows a high magnification image of the area marked Y in Fig. 12 where fracture is completely brittle and characterized by many small facets, some of which are con- 


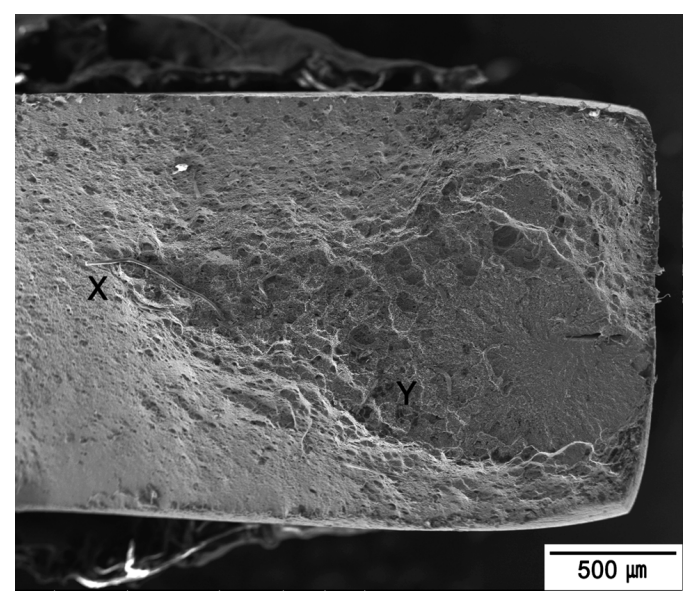

Fig. 12. Analysis of the tensile fracture surface at the end of the sample of a hydrogen charged 10B22 steel after tempering at $150^{\circ} \mathrm{C}$ for $3600 \mathrm{~s}$. SEM micrograph.

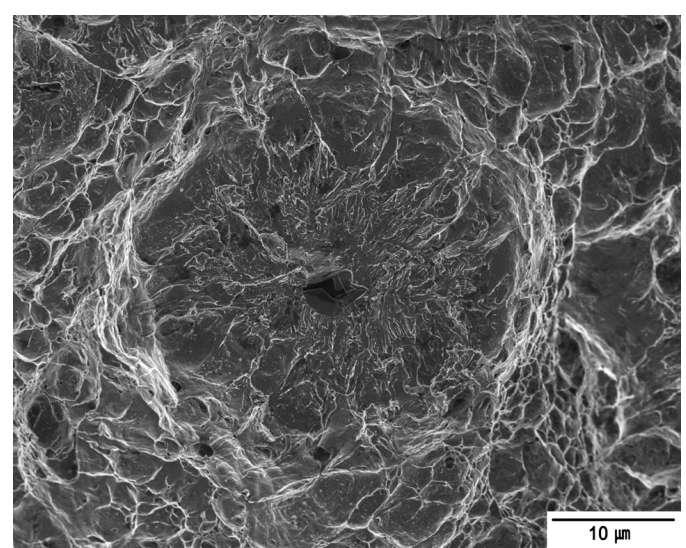

Fig. 13. Transgranular brittle fracture feature from area marked (X) in Fig. 12 on fracture surface of hydrogen charged tensile specimen tempered at $150^{\circ} \mathrm{C}$ for $3600 \mathrm{~s}$. The brittle fracture has nucleated and grown from the inclusion particle in the center of the circular fracture feature and is joined to other similar areas at different elevations by ductile fracture steps. SEM micrograph.

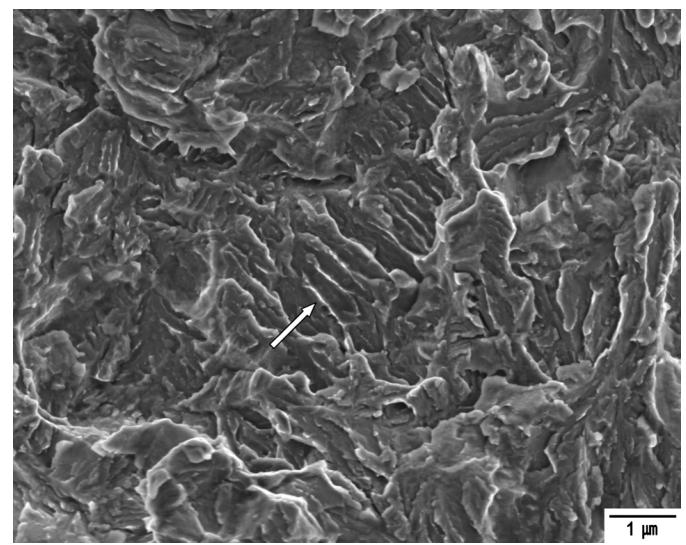

Fig. 14. Fracture surface from area (Y) in Fig. 12 on fracture surface of tensile specimen hydrogen-charged and tempered at $150^{\circ} \mathrm{C}$ for $3600 \mathrm{~s}$. Arrow points to parallel steps of cleavage corresponding to lath martensite crystals in packet or block structure of low-carbon martensitic steel. SEM micrograph.

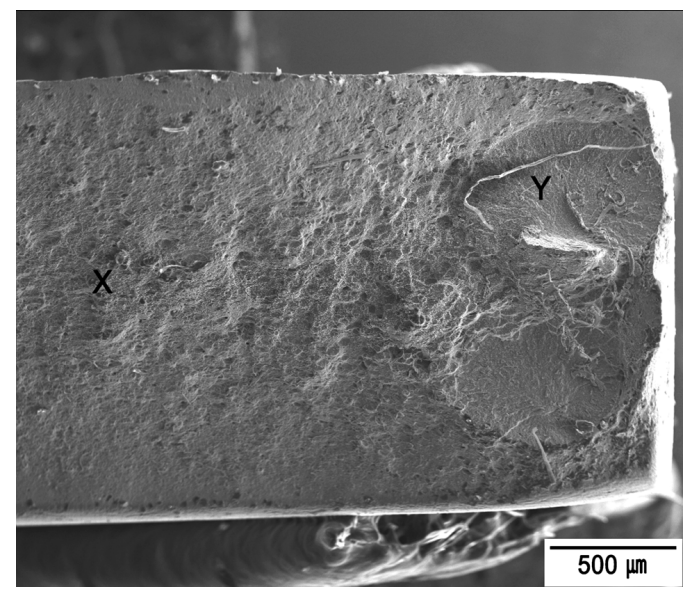

Fig. 15. Analysis of the tensile fracture surface at the end of the sample of a hydrogen charged 10B22 steel after tempering at $250^{\circ} \mathrm{C}$ for $3600 \mathrm{~s}$. SEM micrographs.

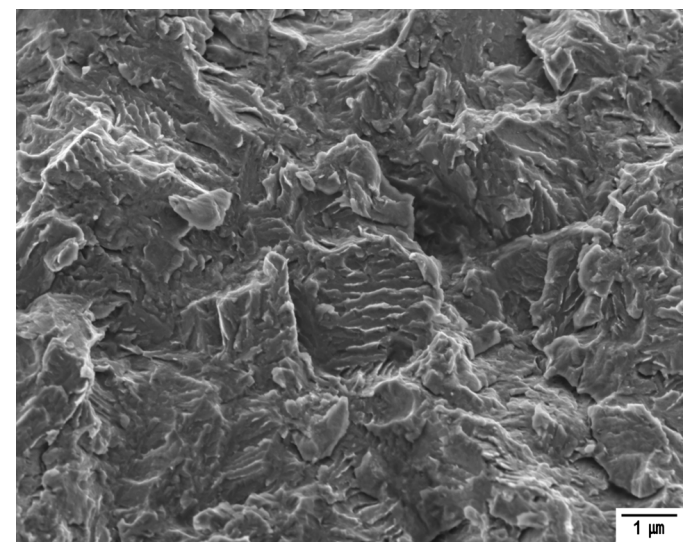

Fig. 16. Fracture from area marked $(\mathrm{Y})$ on fracture surface of hydrogen-charged tensile specimen quenched to martensite and tempered at $250^{\circ} \mathrm{C}$ for $3600 \mathrm{~s}$. The bright parallel features in the center of the micrograph are raised relative to the intervening facets. SEM micrograph.

sistent with fracture of parallel martensite crystals in the blocks or packets typical of lath martensite morphology in low- and medium-carbon steels. The brittle fracture in the circular features in Fig. 13 has the same mix of fine facets as is shown in Fig. 14, and the circular brittle areas are bounded by ductile fracture steps to join similar brittle areas at differing elevations on the fracture surface.

Figure 15 shows a portion of the tensile fracture surface of a specimen hydrogen-charged after quenching and tempering at $250^{\circ} \mathrm{C}$ for $3600 \mathrm{~s}$. A large part of the surface in the area marked $(\mathrm{X})$ has fractured by ductile microvoid coalescence, and brittle fracture occupies the smaller areas marked $(\mathrm{Y})$ on the edges of the specimen. Again, the brittle fracture area is characterized by many small flat facets, as shown in Fig. 16. Some of the facets are consistent with fracture through blocks or packets of parallel martensite crystals, and in these regions, the interlath structure is raised relative to the surrounding facets. Figure 17, a higher magnification image of a different region associated with location Y, clearly shows such parallel raised features. 


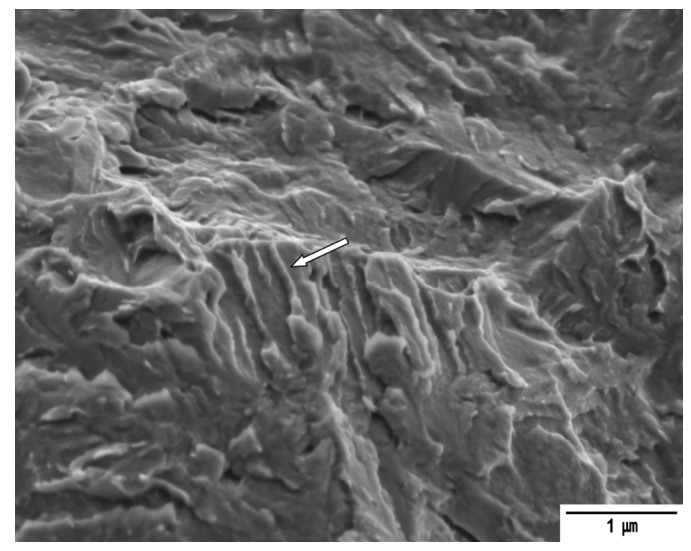

Fig. 17. Another brittle fracture area on fracture surface of tensile specimen tempered at $250^{\circ} \mathrm{C}$ for $3600 \mathrm{~s}$. Arrow points to an area where parallel elevated features separated flat fracture facets. SEM micrograph.

\section{Discussion}

The above results of the effect of as-charged hydrogen on uniaxial tensile deformation behavior and fracture is discussed here relative to the literature characterizing the microstructure and substructure of tempered martensite in low carbon steels ${ }^{23-28)}$ and the literature of hydrogen embrittlement in steels. ${ }^{9-18)}$ As-quenched martensite in low carbon steels consists of a lath morphology where martensite crystals form parallel to one another in blocks, where the crystals have the same orientation, or in packets where orientations may differ. Austenite may be retained, albeit in very small amounts, between parallel martensite crystals, even in steels with low carbon content, as has been shown by Okamoto in an $0.14 \mathrm{wt} \%$ carbon steel. ${ }^{29)}$ The dislocation density within as-quenched lath martensite is very high, on the order of $\left.10^{12} \mathrm{~cm}^{-2} \cdot 30,31\right)$

Tempering at low temperatures, below $200^{\circ} \mathrm{C}$, causes the formation of fine transition carbides and reduces slightly dislocation densities by recovery mechanisms. Retained austenite remains stable in low-temperature-tempered martensite, but at tempering temperatures above $200^{\circ} \mathrm{C}$ transforms to cementite and ferrite. Also above $200^{\circ} \mathrm{C}$ the transition carbides are replaced by coarser cementite particles, and dislocation densities are significantly reduced. At higher tempering temperatures martensite laths coarsen by the elimination of low-angle boundaries, and in view of the relief of the supersaturation of carbon in as-quenched martensite by carbide formation, the matrix becomes bcc ferrite and the ferritic grains become more equiaxed and less lath shaped by recovery, recrystallization and grain growth mechanisms. The transformation of the retained austenite to cementite causes mild effects of tempered martensite embrittlement in the low carbon steel of this investigation, as manifested by the slight reduction in ductility shown in specimens tempered at 150 to $350^{\circ} \mathrm{C}$ in Fig. 8 . The sharp drop in dislocation density and carbide coarsening with increased tempering intensity greatly lowers strain hardening, as shown for the uncharged specimens in Figs. 5 through 7 .

The charging of $1.7 \mathrm{ppm}$ hydrogen to the as-quenched martensitic microstructure causes the most severe embrit- tlement. Figure 2 shows that the hydrogen fracture is stress controlled and fractography shows a fully brittle fracture surface. Although a small amount of intergranular fracture was observed, Fig. 10, fracture was predominantly transgranular, indicating that the boron segregation to austenitic grain boundaries, which provides good hardenability to low carbon steels, had little effect on fracture. Some relatively coarse planar transgranular facets, on the order of packet or block dimensions, were a characteristic feature of the fracture. The severe embrittlement of the as-quenched samples is consistent with the fact that the martensitic microstructure has the highest density of dislocations, which according to Wei and Tsuzaki ${ }^{18)}$ are principal traps for hydrogen. These observations are consistent with severe, low-stress lowering of the cohesive bonding strength of the martensitic crystal structure due to hydrogen charging.

Figures 3 and 4 show that the hydrogen fractures of martensitic specimens tempered at the low temperatures of 150 and $250^{\circ} \mathrm{C}$ are strain controlled, with fracture occurring after a limited amount of plastic strain. Nevertheless, the fracture surfaces at crack initiation are completely brittle, with many small irregular facets and some areas where cracking has clearly developed through parallel martensite crystals in blocks or packets of the lath martensitic microstructure. The brittle fracture facets are consistent with the fracture mechanism described as glide plane decohesion. ${ }^{10,13,14)}$ In this mechanism, hydrogen, which is strongly attracted to the core of dislocations, lowers the stresses for dislocation motion on slip planes but prevents cross slip of screw dislocations, limiting the ability of the microstructure to achieve extensive plastic deformation. The concentration of dislocations and the trapped hydrogen then cause fracture on the $\{110\}$ slip planes of the tempered martensite crystals. Figure 14 shows a fracture area indicated by the arrow where steps, as marked by high secondary electron intensity, are present. These steps indicate that not only has translath hydrogen cleavage developed, but also fracture between laths. These steps of interlath fracture may be the result of hydrogen trapping in the interlath austenite known to be present in low-temperature tempered lath martensite. ${ }^{29)}$ Andreone and Murut $^{37)}$ have shown that, because of the high solubility of hydrogen in austenite, retained austenite may serve as a reservoir for hydrogen in hardened steel, and that 4340 steel with high contents of retained austenite may be strongly embrittled by hydrogen. The steps in hydrogenembrittled lath martensite have also been reported and discussed by Hinotani et al. ${ }^{32}$ )

In contrast to the through-facture of martensite blocks and packets in specimens tempered at $150^{\circ} \mathrm{C}$, the through fracture of martensite blocks and packets in specimens tempered at $250^{\circ} \mathrm{C}$ does not show a mixture of trans- and intercrystalline fracture. Rather, the fracture is completely single-plane transgranular, with the cementite formed by the transformation of austenite in the second stage of tempering merely causing the cleavage fracture in a packet or block to be deflected around the cementitie particles, as shown in Fig. 17. There is no interlath fracture caused by the cementite, confirming the conclusion of Wei and Tsuzaki ${ }^{18)}$ that cementite has a negligible effect on hydrogen trapping.

Figure 13 shows a unique morphology of transgranular 
brittle hydrogen fracture centered on coarse inclusion particles. Brittle fracture with the same characteristics as described above for the specimen tempered at $150^{\circ} \mathrm{C}$ radiates out from an inclusion particle, producing a circular brittle patch with a circumference that terminates with ductile tearing to another level of the fracture surface. This type of hydrogen fracture has been observed in highly tempered 4130 steels, ${ }^{12,33)}$ in heat affected zones of low-carbon steel welds, ${ }^{15}$ and in hardened low carbon steel subjected to slow strain rate tensile testing in a sulfide stress cracking environment. ${ }^{34)}$ Apparently the strong hydrogen trapping capacity of inclusions, often considered to be irreversible traps for hydrogen, ${ }^{35)}$ provides a source or reservoir for hydrogen that causes localized embrittlement, provided local stress concentrations, strain rate, and microstructure combine for embrittlement susceptibility. It should be noted that some brittle fracture zones due to hydrogen embrittlement were separated from other brittle fracture zones by localized regions of ductile failure, i.e. void coalescence. The presence of these regions of ductile failure, in an otherwise embrittled sample, are interpreted to be due to fracture at high localized strain rates that would develop to join non-planar regions of brittle fracture. Specifically it is interpreted that the localized strain rate at a propagating crack front is sufficiently high that diffusion controlled hydrogen embrittlement mechanisms do not have sufficient time to operate and failure occurs by normal ductile mechanisms. The ductile fracture regions at areas marked $X$ in Figs. 9, 12, and 15 are also attributed to the localized high strain rates associated with crack propagation.

In samples tempered at $460^{\circ} \mathrm{C}$ and $520^{\circ} \mathrm{C}$, the lack of hydrogen embrittlement is interpreted to directly reflect the effects of tempering on the martensitic microstructure, as hydrogen content measurements showed that the $1.7 \mathrm{ppm}$ hydrogen was maintained throughout the tests. With tempering, the high dislocation density which developed on martensite formation decreases leading to a decrease in strength. However, the cementite particle density has increased at interlath boundaries and at interfaces between martensite packets and blocks. ${ }^{36}$ ) Thus, although cementite particles are considered to have negligible effects on hydrogen trapping, ${ }^{18)}$ they become the dominant traps in highly recovered (i.e. low dislocation density) martensite, as characterized by tritium autoradiography by Hanada et al. ${ }^{38)}$ Thus, cementite particles may retain sufficient hydrogen to prevent failure during tensile testing by glide plane decohesion as observed in specimens with higher dislocation densities (i.e. in those tempered at lower temperatures).

\section{Conclusions}

The presence of boron, which is added to increase the hardenability of low carbon steels, has little effect on hydrogen embrittlement fracture mechanisms.

As-quenched martensite has the highest susceptibility to hydrogen embrittlement and failed by stress controlled fracture at low strains (i.e. at stresses substantially below the macroscopic yield stress).

The susceptibility to hydrogen embrittlement in 10B22 steel decreased with an increase in tempering temperature, and samples tempered above $460^{\circ} \mathrm{C}$ exhibited properties equivalent to the same steel without hydrogen charging.

Inclusions were shown to nucleate localized regions of hydrogen induced brittle fracture and were interpreted to provide both regions of localized stress concentration and participate as reversible traps that provided localized regions with high hydrogen concentrations.

\section{Acknowledgements}

The authors gratefully acknowledge the support of the sponsors of the Advanced Steel Processing and Products Research Center, an industry/university cooperative research center at the Colorado School of Mines. The authors also thank Dr. John Chandler at CSM for his assistance with the scanning electron microscopy.

\section{REFERENCES}

1) C. D. Horvath and J. R. Fekete: Proc. of Int. Conf. on Advanced High Strength Sheet Steels, AIST, Warrendale, PA, (2004), 3.

2) G. Schieß1, T. Possehn, T. Heller and S. Sikora: Manufacturing a Roof frame from Ultra High Strength Steel Materials by Hot Stamping, Proc. of International Deep Drawing Research Group Conf. 2004, Sindelfingen Germany, (2004), 158.

3) M. Naderi, V. Uthaisangsuk, U. Prahl and W. Bleck: Steel Res. Int., 79 (2008), 77.

4) P. Hein and J. Wilsius: Steel Res. Int., 79 (2008), 85.

5) M. Maikranz-Valentin, U. Weidig, U. Schoof, H. H. Becker and K. Steinhoff: Steel Res. Int., 79 (2008), 92.

6) J. Lecher, M. Merlein and M. Geiger: Steel Res. Int., 79 (2008), 98.

7) M. Säglitz, D. K. Matlock and G. Krauss: Proc. of Int. Conf. on New Developments in Advanced High Strength Steels, AIST, Warrendale, PA (2008), 147.

8) M. Säglitz, G. Krauss, D. K. Matlock and M. Niegel: J. Heat Treat. Mater. (HTM), 3 (2009), 136.

9) H. H. Johnson, J. G. Morlet and A. R. Troiano: Trans. TMS-AIME, 212 (1958), 528.

10) J. P. Hirth: Metall. Trans. A, 11A (1980), 861.

11) S. K. Banerji, C. J. McMahon, Jr. and H. C. Feng: Metall. Trans. A, 9A (1978), 237.

12) B. D. Craig and G. Krauss: Mertall. Trans. A, 11A (1980), 1799.

13) F. Nakasato and I. M. Bernstein: Metall. Trans. A, 9A (1978), 1317.

14) Y. Takeda and C. J. McMahon, Jr.: Metall. Trans. A, 12A (1981), 1255.

15) K. Easterling: Introduction to the Physical Metallurgy of Welding, Butterworths, London, (1983), 180.

16) R. Kolleck, R. Veit, and C. Koroschetz: Material Property Data for More Effective Numerical Analysis, Proceedings of International Deep Drawing Research Group Conference 2009, Colorado School of Mines, Golden, CO, USA, (2009), 825

17) M. Wang, E. Akiyama and K. Tsuzaki: Scr. Mater., 52 (2005), 403.

18) F. G. Wei and K. Tsuzaki: Scr. Mater, 52 (2005), 467.

19) S. Komazazki, S. Watanabe and T. Misawa: ISIJ Int., 43 (2003), 1851.

20) P. Bruzzani, G. Domizzi, M. I. Luppo, D. Zalaman and J. OvejeroGarcia: Hydrogen Effects in Materials, ed. by A. W. Thompson and N. R. Moody, TMS, Warrendale, PA, (1996), 1001.

21) J. A. Ronevich: M.S. Thesis, Colorado School of Mines, Golden, Colorado, USA, (2009).

22) ASM Metals Handbook: Fractography, Vol. 12, ed. by K. Mills, ASM Int., Metals Park, OH, (1987), 13.

23) A. R. Marder and G. Krauss: Trans. Am. Soc. Met., 62 (1969), 957.

24) T. Maki, K. Tsuzaki and I. Tamura: Trans. Iron Steel Inst. Jpn., 20 (1986), 207.

25) J. M. Marder and A. R. Marder: Trans. Am. Soc. Met., 62 (1969), 1.

26) T. Swarr and G. Krauss: Metall. Trans. A, 7A (1976), 41.

27) C. A. Apple, R. N. Caron and G. Krauss: Metall. Trans., 5 (1974), 593.

28) R. N. Caron and G. Krauss: Metall. Trans., 3 (1972), 2381.

29) S. Okamoto: M. S. Thesis, Colorado School of Mines, Golden, Colorado, USA, (1990). 
ISIJ International, Vol. 50 (2010), No. 2

30) G. R. Speich: Trans. TMS-AIME, 245 (1969), 2552.

31) S. Morito, J. Nishikawa, and T. Maki: ISIJ Int., 43 (2003), 1475.

32) S. Hinotani, Y. Ohmori and F. Terasaki: Mater. Sci. Eng., 76 (1985), 57

33) B. Craig and G. Krauss: Hydrogen Effects in Metals, ed. by I. M. Bernstein and A. W. Thompson, TMS-AIME, Warrendale, PA, (1981), 795.

34) J. Sojka, M. Jérôme, M. Sozańska, P. Váňová, L. Rytírová and P. Jonšta: Mater. Sci. Eng. A, 480A (2008), 237.
35) G. M. Pressouyre: Metall. Trans. A, 10A (1979), 1571.

36) M. S Säglitz, G. Krauss, and D. Berger: Material Property Data for More Effective Numerical Analysis, Proceedings of International Deep Drawing Research Group (IDDRG) 2009 Conference, ed. by B. S. Levy, D. K. Matlock and C. J. Van Tyne, Colorado School of Mines, Golden, CO, (2009), 637.

37) C. Andreone and A. Murut: Scr. Metall., 24 (1990), 1453.

38) H. Hanada, T. Otsuka, H. Nakashima, S. Sasaki, M. Hayakawa and M. Sugisaki: Scr. Mater, 53 (2005), 1279. 